\title{
Multiaxial high cycle fatigue damage mechanisms associated with the different microstructural heterogeneities of cast aluminium alloys
}

\author{
Viet-Duc LE ${ }^{\mathrm{a}, \mathrm{b}, \mathrm{c}, *}$, Franck MOREL ${ }^{\mathrm{a}}$, Daniel BELLETT ${ }^{\mathrm{a}}$, Nicolas SAINTIER $^{\mathrm{b}}$, Pierre OSMOND $^{\mathrm{c}}$ \\ ${ }^{a}$ Arts et Métiers ParisTech, CER Angers - Laboratoire LAMPA - 2 Bd du Ronceray, 49035 Angers Cedex 1, FRANCE \\ ${ }^{b}$ Arts et Métiers ParisTech, CER Bordeaux - Laboratoire I2M - Esplanade des Arts et Mtiers, 33405 TALENCE \\ Cedex, FRANCE \\ ${ }^{c}$ PSA Pengeot Citroën, 18 rue des fauvelles, 92256 La Garenne-Colombes cedex, FRANCE
}

\begin{abstract}
This article is dedicated to the high cycle fatigue (HCF) behaviour of cast Al-Si alloys. In particular, three similar alloys with different microstructural characteristics are investigated. The result of an experimental campaign are presented, in order to characterise the fatigue behaviour, and more specifically the fatigue damage mechanisms related to the different microstructural heterogeneities (i.e. casting porosity, dendrite size, SDAS, non-metallic inclusions and silicon particles), observed under different multiaxial loading conditions: pure tension, plane bending, pure torsion and combined tension-torsion with a load ratio $\mathrm{R}=-1$.

It is shown that casting porosity has a very detrimental influence on the uniaxial and combined tension-torsion fatigue strengths. However, a much lower influence is observed for the torsional fatigue strength.

For the porosity-free alloy, it is observed that the formation of persistent slip bands (PSB) in the aluminium matrix is the major fatigue crack initiation mechanism regardless of the loading modes, at a load ratio of $\mathrm{R}=-1$. It is also shown that the aluminium matrix has a large role in the formation of PSB and that the Si particles facilitate the formation of PSB.

Keywords: EBSD; aluminum alloys; casting; fatigue; SDAS; defect;
\end{abstract}

\footnotetext{
${ }^{*}$ Corresponding author: Viet-Duc LE

Email address: viet-duc.le@ensam.eu (Viet-Duc LE)
} 


\section{Introduction}

Automotive manufacturers have the choice of several casting processes and post-casting heat treatments for the fabrication of cast aluminium components, such as cylinder heads, used in their vehicles. Typical casting processes include gravity die casting and lost foam casting (LFC) and the components are subsequently heat treated via standard T6 or T7 treatments and/or the HIP treatment. Each casting process and heat treatment combination has certain advantages and disadvantages. From a material point of view, each casting process-post casting treatment combination results in a different microstructure, which can be characterised by the following microstructural features:

- casting defect, notably micro-shrinkage pores and gas porosity;

- the aluminium matrix, often characterised by the DAS (dendrite arm spacing), the SDAS (secondary dendrite arm spacing) and the precipitation hardening level;

- inclusions, in particular silicon particles in the eutectic zones and intermetallics.

The influence of these factors on the HCF behaviour of these materials has been investigated by many researchers. The effect of casting porosity has been studied by [1 $1-4]$ and the effect of the microstructure (i.e. the aluminium matrix and the silicon particles) by [5-7]. However, these studies are often limited to uniaxial fatigue behaviour.

The principal aim of this work is to investigate the influence of different microstructural heterogeneities found in cast aluminium-silicon alloys on the HCF behaviour for different loading modes. Specifically, the fatigue damage mechanisms associated with the microstructural features discussed above are investigated. In order to achieve this aim, an extensive multiaxial HCF testing campaign was conducted, including uniaxial tension-compression loads, pure torsion and combined tension-torsion, on three different Al-Si alloys. These alloys were fabricated by three different processes and therefore they have significantly different microstructures, particularly in terms of their casting defect populations. 


\section{Cast aluminium alloys under investigation}

Fig.11 shows typical microstructural images of the aluminium alloys under investigation which highlight the different microstructural heterogeneities discussed above.

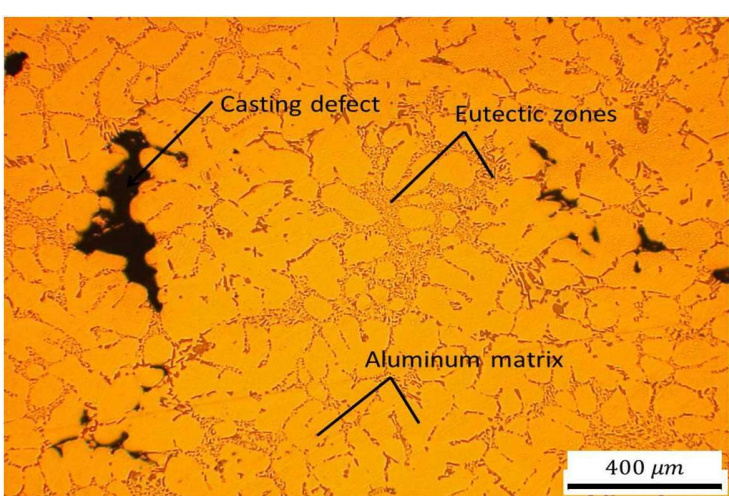

(a)

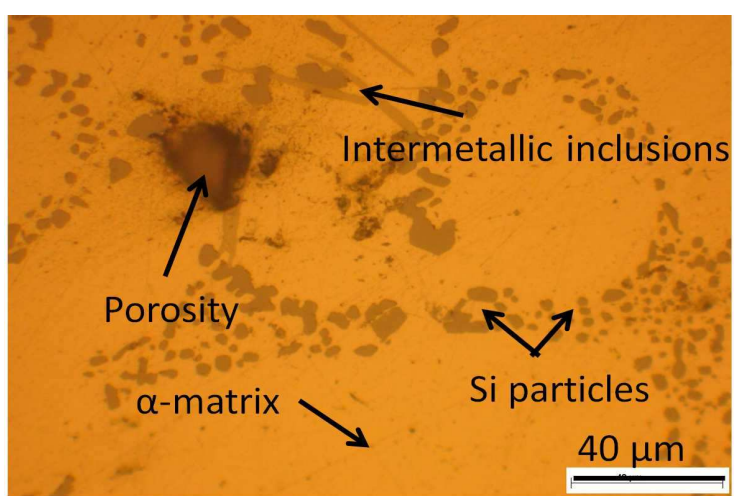

(b)

Figure 1: Microstructural heterogeneities present in the cast aluminium alloys under investigation: a) Typical microstructure of cast aluminium alloys; b) Zoomed view

\subsection{Manufacturing processes for the three investigated alloys} elaborated by either gravity die casting or lost foam casting and then were subjected to either a standard T7 heat treatment or a Hot Isostatique Pressing (HIP) followed by a T7 treatment (see $\mathrm{Tab} 10$

Alloy A corresponds to the gravity die cast material introduced in the work of Koutiri et al.[1].

Lost foam casting is used to fabricate alloys B and C and the material is cast in the form of plates, $200 \mathrm{~mm} \times 150 \mathrm{~mm} \times 18 \mathrm{~mm}$ in size. This leads to a material with a high porosity volume 

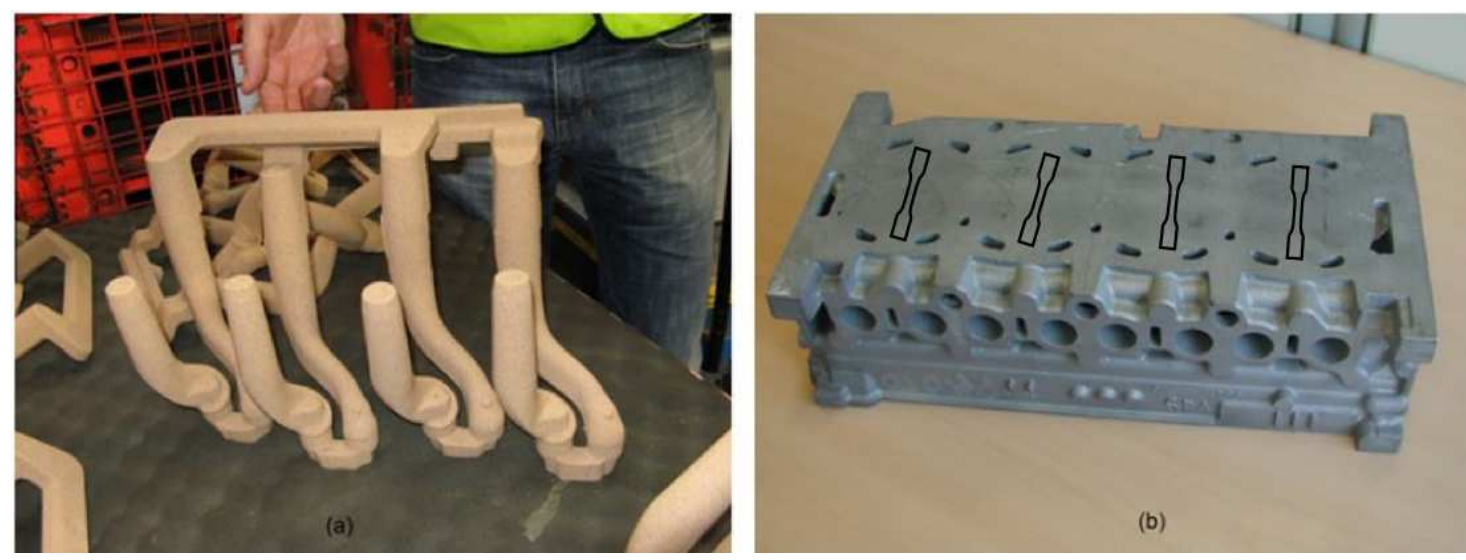

Figure 2: (a) Modified cores used to shape the inlet and exhaust passages. (b) Cylinder head after modification [1].

fraction. Consequently, it should be noted that the microstructure and defect size distribution of alloys B and C are not representative of the material present in industrially cast cylinder heads.

The two post-casting heat treatments are presented below:

- HIP treatment: tempering at a temperature of approximately $500^{\circ} \mathrm{C}$ under a pressure of approximately 1000 bars

- T7 heat treatment:

- Solution heat-treatment for 5 hours at a temperature of 535 to $540^{\circ} \mathrm{C}$,

- Water quenching at a temperature of 60 to $70^{\circ} \mathrm{C}$,

- Tempering at $200^{\circ} \mathrm{C}$ for 5 to 5.5 hours,

- Cooling in ambient air.

Tab. 11 lists the chemical compositions, casting processes and heat treatments for each of the investigated materials.

\subsection{Microstructure characterization and monotonic mechanical properties}

The aluminium matrix.

The primary alpha matrix is typically characterized by the Secondary Dendrite Arm Spacing (SDAS). This quantity is determined by identifying individual aluminium dendrites, the SDAS 


\begin{tabular}{cccc}
\hline Material & Chemical Composition (wt.) & Casting process & Heat Treatment \\
\hline A & $7 \% S i, 0.3 \% \mathrm{Mg}, 0.2 \% \mathrm{Fe}, 0.5 \% \mathrm{Cu}$, Remainder Al & Gravity Die Cast & T7 \\
B & $7 \% \mathrm{Si}, 0.3 \% \mathrm{Mg}, 0.2 \% \mathrm{Fe}$, Remainder Al & Lost Foam Cast & T7 \\
$\mathrm{C}$ & $7 \% \mathrm{Si}, 0.3 \% \mathrm{Mg}, 0.2 \% \mathrm{Fe}$, Remainder Al & Lost Foam Cast & HIP+T7 \\
\hline
\end{tabular}

Table 1: Chemical compositions, casting process and heat treatment used to elaborate the three material under investigation

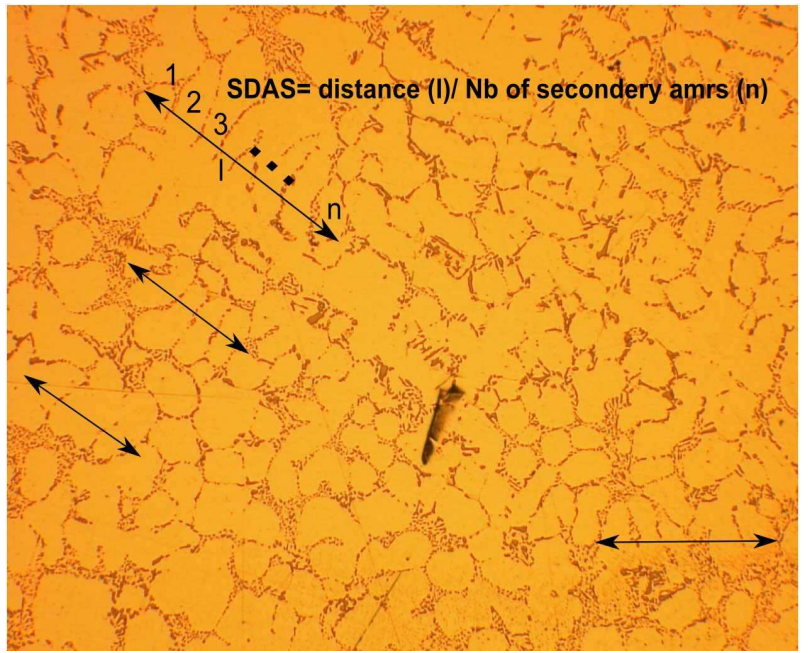

(a)

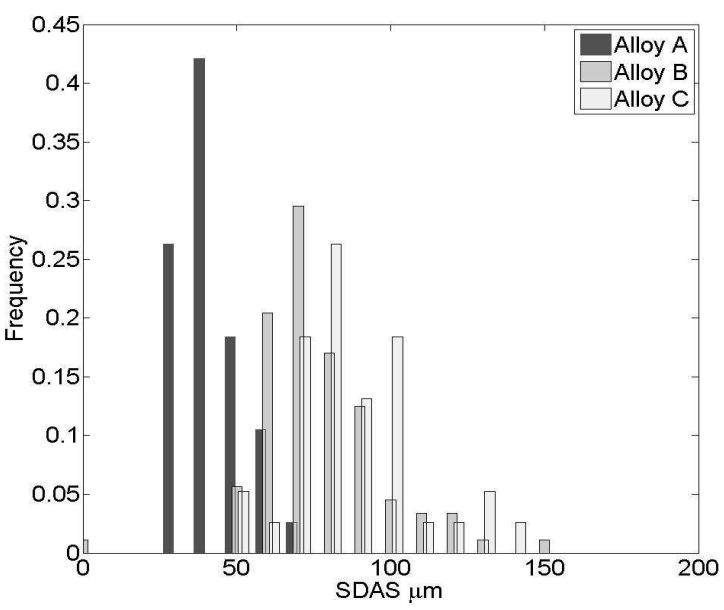

(b)

Figure 3: SDAS measurement method (a) and the SDAS distribtions of three materials under investigation (b)

is then measured as the distance between the secondary dendrite arms (Fig, 3(a) . Forty dendrites

60 Fig. 3(b), It can be seen that the SDAS of alloy A $\left(S D A S_{A}=42.3 \pm 9.7 \mu m\right)$ is the smallest while that of material B $\left(S D A S_{B}=77.3 \pm 18.9 \mu m\right)$ and $\mathrm{C}\left(S D A S_{C}=91.4 \pm 32.8 \mu m\right)$ are larger. For the casting of aluminium alloys the SDAS is inversely proportional to solidification rate [5]. As such the difference in the SDAS between alloys $\mathrm{A}$ and $\mathrm{B} / \mathrm{C}$ can be explained by the fact that the solidification rate in gravity die casting in which metallic moulds are used (for alloy A) is greater than that in lost foam sand casting (alloys B and C).

As regard to the dendrite size, EBSD measurements have been conducted to characterize the distribution of the dendrite size. Three samples of alloys A and C with the same geometry as the 
fatigue specimens (Fig,7(a)], but with a flat zone on the cylindrical section (see Fig.7(b)) were 70 prepared. The surface was firstly mechanically polished and then electrochemically etched using a 20:80 (\%volume) $\mathrm{HNO} 3 / \mathrm{CH} 4 \mathrm{Co}$ solution at 0 to $5^{\circ} \mathrm{C}$ and $15 \mathrm{~V}$ for $10 \mathrm{~s}$. The spatial resolution of EBSD measurements is $5 \mu m \times 5 \mu m$. Fig 4 shows an EBSD inverse pole figure cartography.

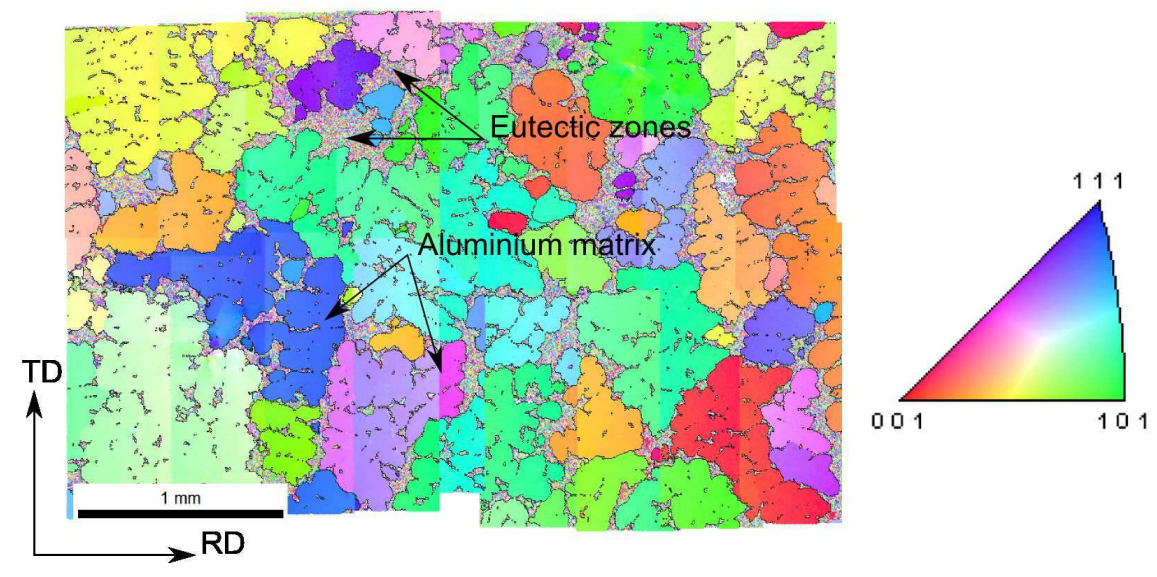

Figure 4: Inverse pole figure corresponding to the ND direction of the $\mathrm{C}$ sample

Using the data obtained by EBSD measurements, the grain size distributions are determined (Fig. 5). Note that these distributions are not based on the percentage of number of grains but on the grain area percentage. The average grain size $D_{e, \text { average }}$ is then determined by Eq[1][8]:

$$
D_{\text {e,average }}=\Sigma_{i}\left(D_{e_{i}} \cdot f_{i}\right)
$$

where $D_{e, i}$ is the equivalent diameter of grain $i$ calculated from the area of grain $i$, area $a_{i}$, by Eq, 2 , and $f_{i}$ is the grain size percentage of grain $i$.

$$
D_{e, i}=\sqrt{\frac{4 \times \text { area }_{i}}{\pi}}
$$

The average grain size of alloy $\mathrm{A}(337 \mu \mathrm{m})$ is smaller than that of alloy $\mathrm{C}(464 \mu \mathrm{m})$. This difference is in agreement with the results obtained for the SDAS of these two alloys (Fig 3(b)).

In addition, the micro-hardnesses of the alpha phase of the three alloys were measured (see Tab,2). It can be seen that the micro-hardness of the alloy A is the highest while alloys B and C are approximately the same order of magnitude. In fact, alloy A contains an additional $0.5 w t . \%$ 


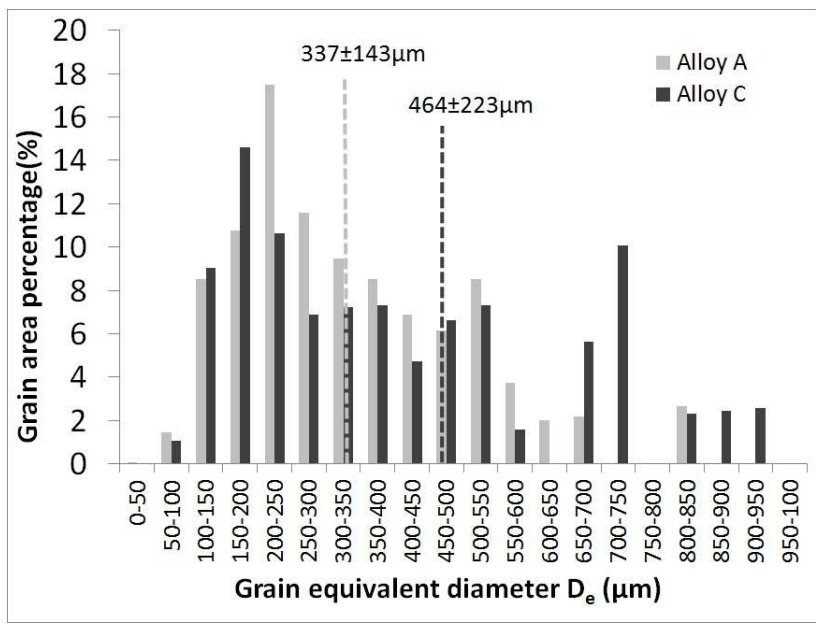

Figure 5: Grain size considering the grain size percentage distributions of alloys $\mathrm{A}$ and $\mathrm{C}$

\begin{tabular}{cc}
\hline Alloy & Micro-hardness $(\mu \pm s)($ HV0.025) \\
\hline A & $114 \pm 3$ \\
B & $99 \pm 9$ \\
C & $92 \pm 13$ \\
\hline
\end{tabular}

Table 2: Micro-hardness of the aluminium matrix of the three investigated alloys

copper, compared to the alloys B and C. The presence of copper in the chemical composition results in a higher micro-hardness of the alpha phase.

80

\section{Pore characterization.}

In order to characterize the size distribution of the casting defect (degassing and micro-shrinkage pores) in these materials, two different methods are used: the metallography methodology proposed by Murakami [9] and a second approach based on observations of the fatigue failure surfaces.

- The metallography methodology: the defect size distribution is determined from optical microscopic observations of polished samples. In particular, the maximum defect size in each standard inspection area of size $S_{0}$, is measured.

- Observations of the failure surfaces: the failure surface of each specimen, tested in fatigue, was examined to identify and measure the size of the casting defect at the origin of the 

alloy C.

The defect size distributions determined for the three alloys, determined by the metallography methodology, are shown in Fig.6(a) and the distributions based on observations of the failure surfaces for alloys A and B are shown in Fig.6(b).

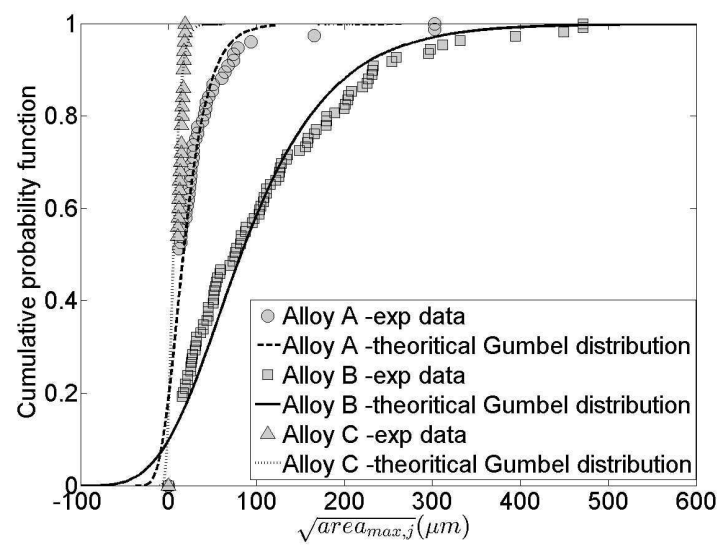

(a)

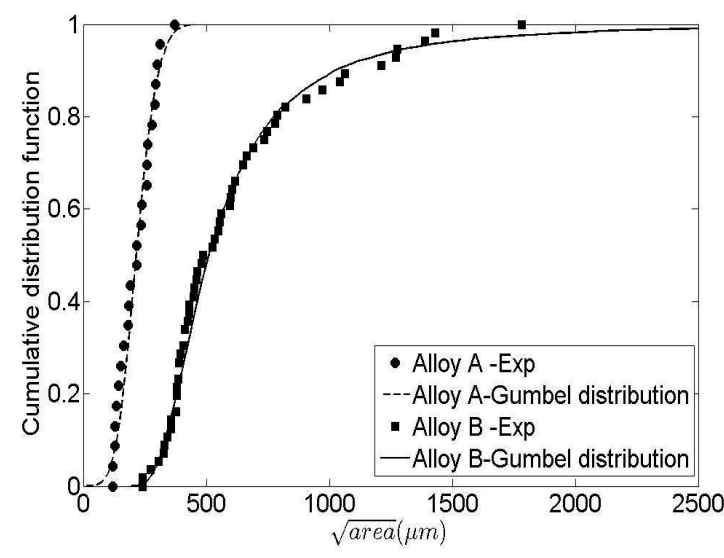

(b)

Figure 6: Defect size distributions characterised by the two different methodologies: a) by the metallography methodology; b) by the observations of the failure surfaces

It shows that the defect sizes measured by the second method are much larger than those obtained by the first method. In fact, the distribution obtained by the first method correspond to the extreme value distribution related to the area $S_{0}$ while the distribution determined by the second method is based on the assumption that the pore at the origin of the the fatigue failure is the largest pore in the uniformly loaded volume. As such it corresponds to the extreme value distribution related to the critical defects in the total loaded volume. Because the sizes of these two observation zones are very different, the maximum defect sizes observed are different.

Because the obtained distributions correspond to the extreme value distribution, the Gumbel distribution has been used to fit the experimental data. It can be seen that the Gumbel distribution results in a very good approximation for alloys A and B for both methods.

Monotonic mechanical properties.

The resulting mechanical properties of three alloys are listed in Tab. 3 . 


\begin{tabular}{ccccc}
\hline Alloy & $\begin{array}{c}\text { Young's modulus } \\
\mathrm{E}(\mu \pm s)(\mathrm{GPa})\end{array}$ & $\begin{array}{c}0.2 \% \text { Yield stress } \\
\sigma_{y}(\mu \pm s)(\mathrm{MPa})\end{array}$ & $\begin{array}{c}\text { Ultimate tensile strength } \\
\sigma_{u t s}(\mu \pm s)(\mathrm{MPa})\end{array}$ & $\begin{array}{c}\text { Elongation } \\
(\mu \pm s)(\%)\end{array}$ \\
\hline A & $77 \pm 6$ & $260 \pm 2$ & $304 \pm 4$ & $4.7 \pm 1.2$ \\
B & $68 \pm 5$ & $240 \pm 5$ & $251 \pm 6$ & $0.8 \pm 1.2$ \\
C & $74 \pm 3$ & $250 \pm 3$ & $275 \pm 5$ & $2.3 \pm 0.7$ \\
\hline
\end{tabular}

Table 3: Mechanical properties of the three alloys

It is shown that all the mechanical properties (the Young modulus, yield stress, ultimate tensile strength and elongation) of alloy A are higher than that of alloy $\mathrm{C}$, even though alloy A contains porosity and alloy $\mathrm{C}$ is porosity-free. However, it must keep in mind that the alloy A has not only a finer microstructure than the alloy $\mathrm{C}\left(S D A S_{A}<S D A S_{C}\right)$ but also a higher micro-hardness of the alpha phase. These factors can significantly improve the mechanical properties of cast Al-Si alloys ([10] [11] [12]).

\subsection{Experimental conditions: fatigue tests}

All of the fatigue tests presented below were carried out at ambient temperature and pressure in laboratory air. All of the fatigue tests were conducted with the same specimen geometry, showed in figure 7(a), All of the fatigue specimens were mechanically polished after machining using (a) abrasive paper (b) followed by polishing using a diamond paste down to $1 \mu \mathrm{m}$ in size and (c) finally an Active Oxide Polishing Suspensions was used.

Tab 4 summarizes the fatigue testing conditions of the three loading conditions investigation. In order to determine the fatigue strength, the staircase technique was used with a maximum life of $2 \times 10^{6}$ cycles. The stopping criteria were chosen to ensure the presence of a fatigue crack of approximately $3 \mathrm{~mm}$ in length.

\section{Fatigue strength for different loading conditions}

Fig 8(a), 8(b) and 8(c) show the experimentally determined Wöhler diagrams for alloys A, $\mathrm{B}$ and $\mathrm{C}$, for the different loading modes. Note that for the combined tension-torsion loading condition the stress amplitude shown on the diagram corresponds to the axial stress $\sigma_{x x, a}\left(\sigma_{x x, a}=\right.$ 

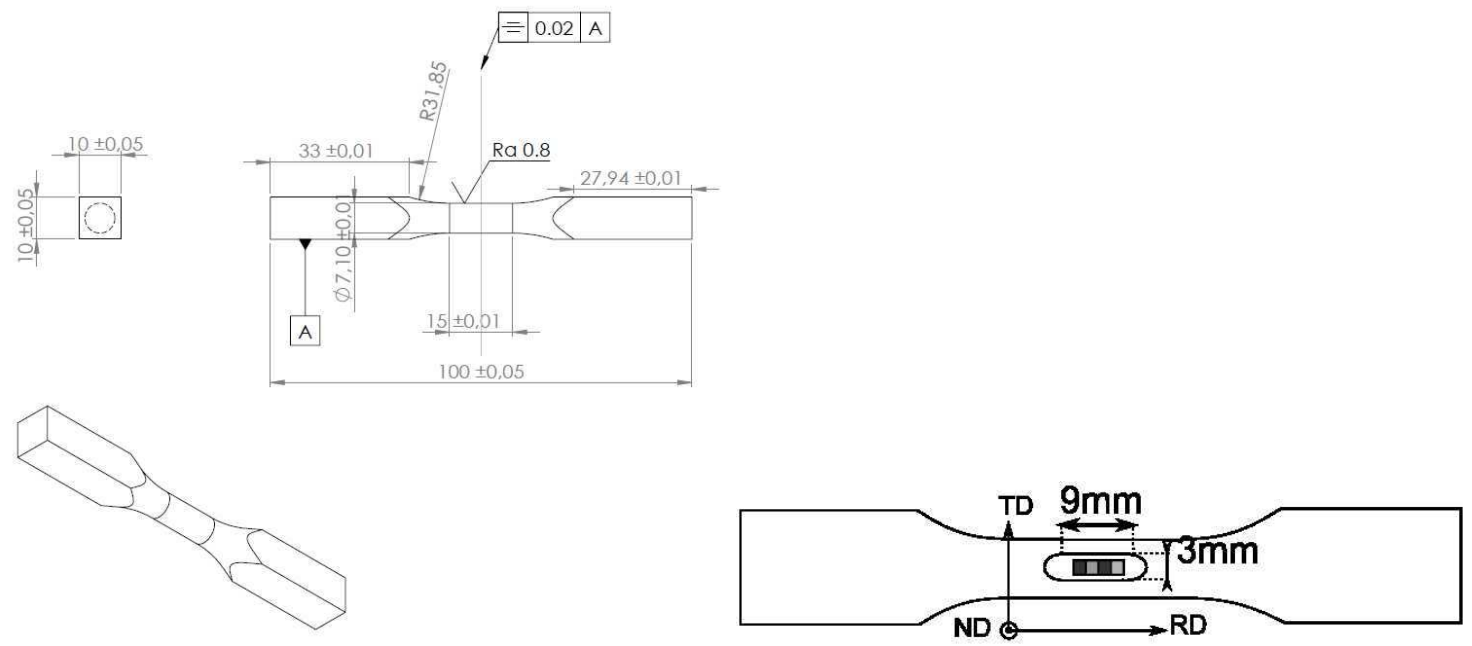

(a)

(b)

Figure 7: Specimen for tension, torsion and combined tension-torsion fatigue tests (a) and dimensions of flat zone polished on the fatigue specimen used for EBSD observations (b)

\begin{tabular}{ccccc}
\hline Load & Load ratio & Biaxiality ratio & Machine & Frequency \\
& $\mathrm{R}$ & $\mathrm{k}$ & & $\mathrm{Hz}$ \\
\hline Pure tension & -1 & N/A & Resonant & $90-100$ \\
Pure torsion & -1 & N/A & Resonant & $70-90$ \\
Combined tension-torsion & -1 & 0.5 & Electromagnetic & $20-30$ \\
\hline
\end{tabular}

Table 4: Fatigue test conditions for different loading modes

$\left.2 \tau_{x y, a}\right)$. The curves passing through the experimental data correspond to the Basquin equation $\sigma_{x x, a}=a \cdot N^{m}$. The fatigue strengths at $2 \times 10^{6}$ cycles are presented in $\tau-\sigma$ space (or on the Gough-Pollard) diagram in Fig 9 . The error bars correspond to a failure probability of $10 \%$ to $90 \%$, calculated from the standard deviations obtained thank to the stair-case technique.

$\mathrm{Tab} 5$ summarises the fatigue strengths, in terms of the mean value $\mu$ and standard deviation $s$ of the three investigated alloys at $2 \times 10^{6}$ cycles.

Firstly, it can be seen that for the tension-compression and combined tension-torsion loading conditions, the fatigue strength of alloy $\mathrm{C}$ are the greatest and that of alloy $\mathrm{B}$ is the smallest. This tendency is in agreement with the casting defect populations determined for the three alloys (see 


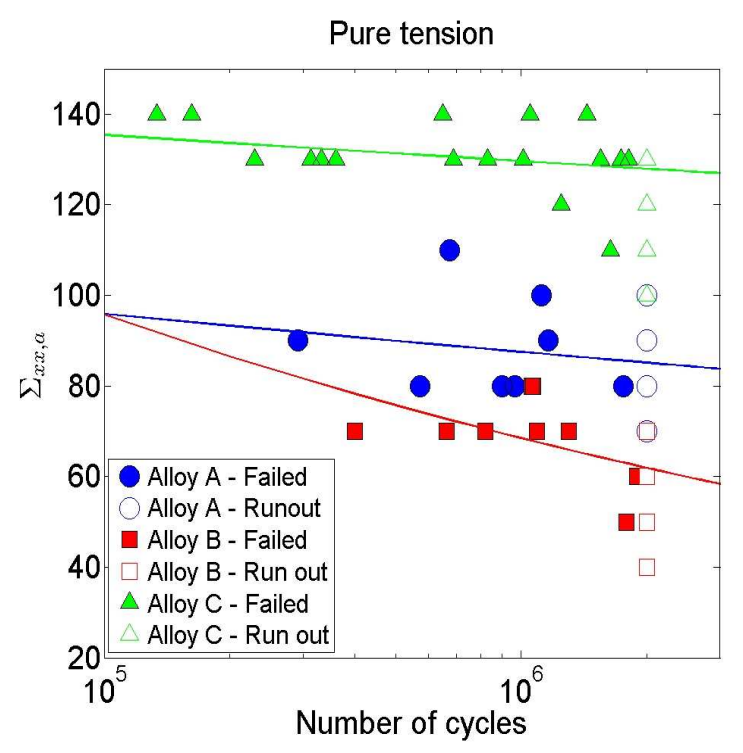

(a)

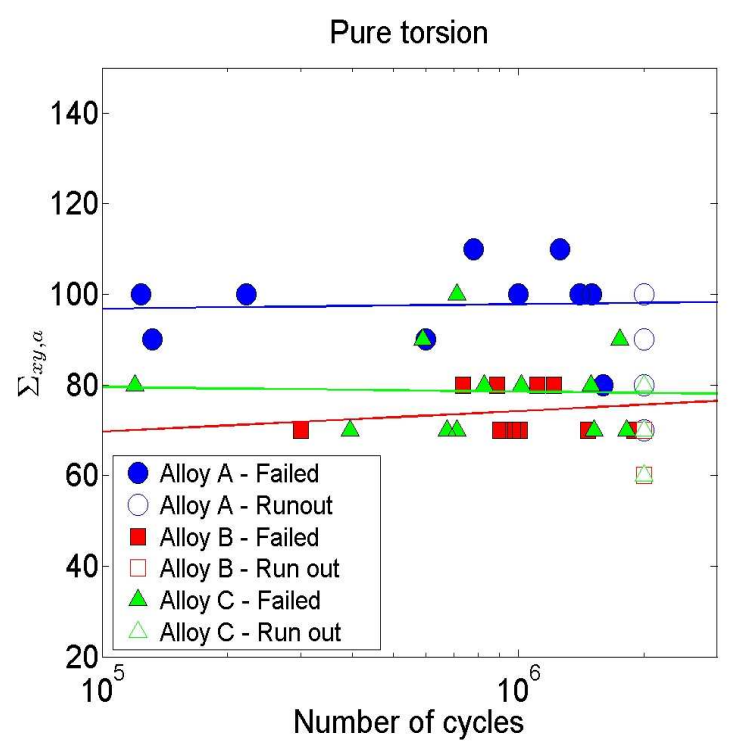

(b)

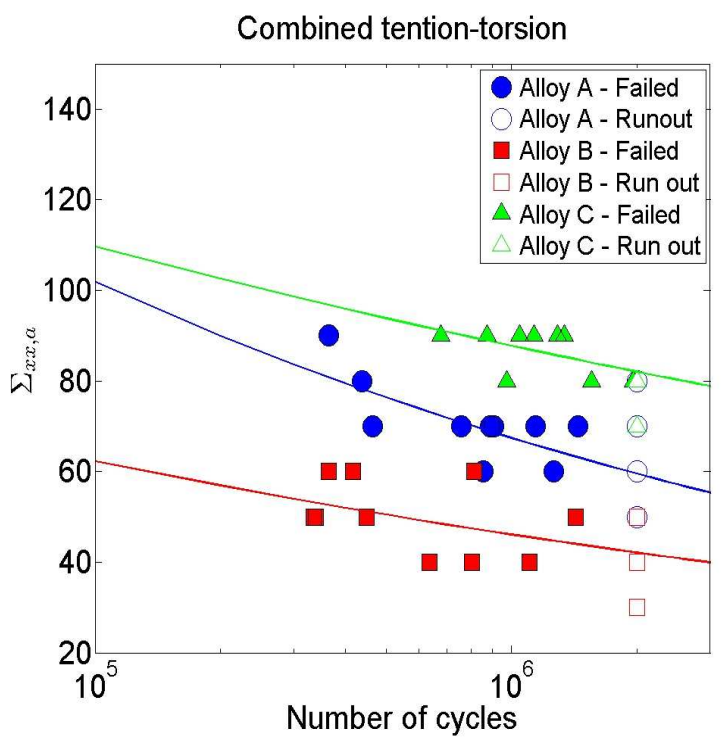

(c)

Figure 8: Wöhler diagrams for alloys A, B and C for: a) uniaxial tensile loads $\mathrm{R}=-1$; b) reversed torsion load $\mathrm{R}=-1$ (b); c) combined tension-torsion load $\mathrm{R}=-1$

Fig 6(a) . For the purely torsional loads, a surprising result is observed: the fatigue strengths of alloys B and C are of the same order of magnitude, while alloy A has the highest fatigue strength.

A very interesting result is the change in the ratio between the torsional fatigue strength and the uniaxial fatigue strength $\left(\tau_{a, D} / \sigma_{a, D}\right)$ : for the porosity-containing alloys (alloys A and B), 


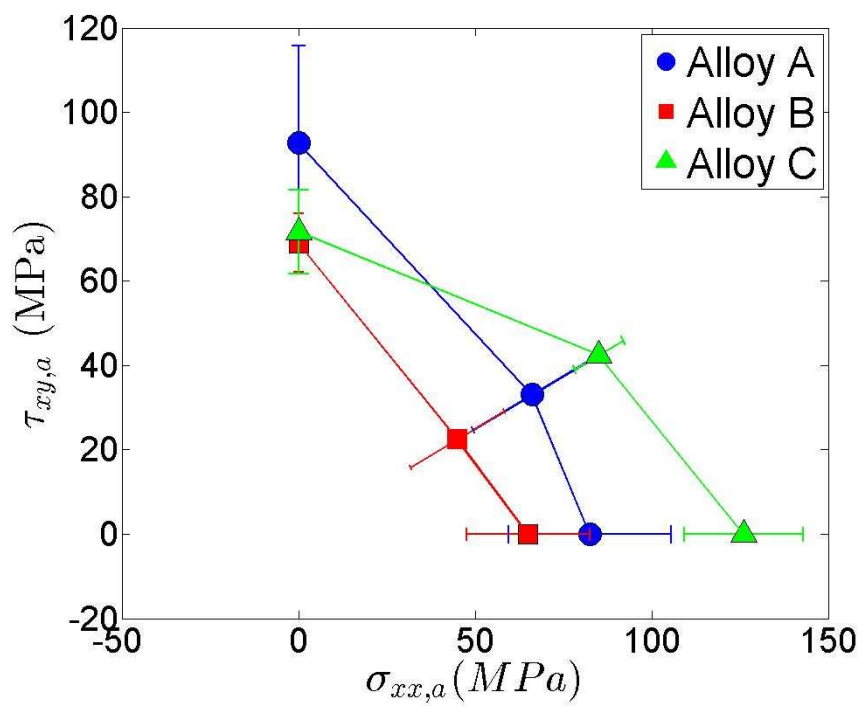

Figure 9: $\tau_{x y, a}-\sigma_{x x, a}$ diagram of three studied alloys

\begin{tabular}{cccc}
\hline Alloy & $\begin{array}{c}\text { Pure tension (alloys B and C) } \\
\text { Plane bending (alloy A) }(\mu \pm s)(\mathrm{MPa})\end{array}$ & $\begin{array}{c}\text { Pure torsion } \\
(\mu \pm s)(\mathrm{MPa})\end{array}$ & $\begin{array}{c}\text { Combined tension-torsion } \\
\sigma_{x x, a}\left(=2 \tau_{x y, a}\right)(\mu \pm s)(\mathrm{MPa})\end{array}$ \\
\hline A & $83 \pm 18$ & $93 \pm 14$ & $66 \pm 13$ \\
\hline B & $65 \pm 13$ & $69 \pm 5$ & $49 \pm 10$ \\
\hline C & $126 \pm 13$ & $72 \pm 8$ & $80 \pm 5$ \\
\hline
\end{tabular}

Table 5: Summary of the fatigue strengths of the three alloys at $2 \times 10^{6}$ cycles for different multiaxial loading loads

$\tau_{a, D} / \sigma_{a, D} \approx 1$ while for the porosity-free alloy (alloy C), $\tau_{a, D} / \sigma_{a, D}=0.57$.

Another important point to consider is the scatter associated with the fatigue strength. The relative standard deviation (RSD), determined by Eq, 3 , is used to estimate the scatter.

$$
R S D=\frac{S}{\mu}
$$

where $\mu$ and $s$ are the mean value and the standard deviation of the experimentally determined fatigue strength. For the combined tension-torsion load, the axial fatigue amplitude $\left(\sigma_{x x, a, D}\right)$ is used in this calculation.

Fig 10 shows the relative standard deviation of the three investigated alloys for different loading modes. It is shown that the RSD of the porosity-free alloy (alloy C) for the tension-compression 
and combined tension-torsion loading conditions is lower than that of the porosity-containing alloys (alloys A and B).

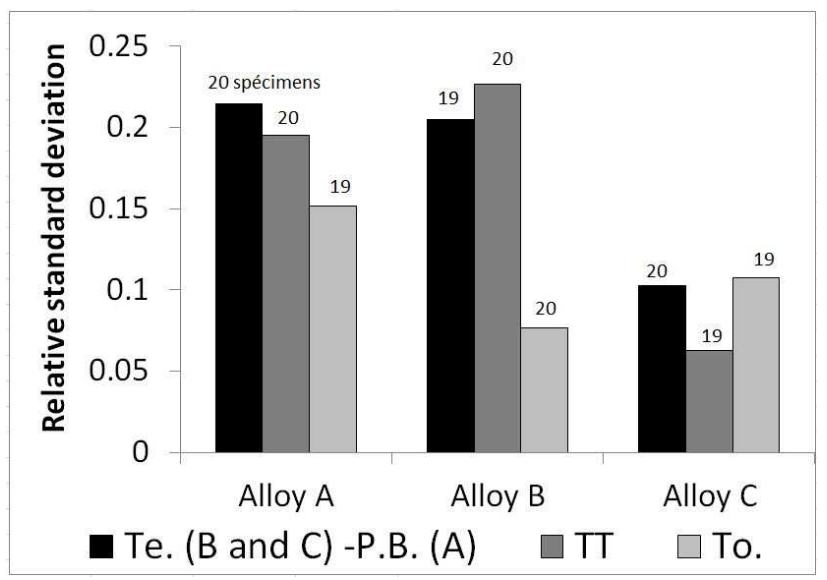

Figure 10: Comparison of relative standard deviation associated with the fatigue strength of alloys A,B and C for different loading modes: Pure tension (Te.), Plane bending (P.B.), combined tension-torsion (TT) and pure torsion (To.)

\section{Fatigue crack initiation and crack growth mechanisms under different loading modes}

\subsection{Uniaxial loading}

\subsubsection{Porosity-containing materials (alloys $A$ and B)}

Surface observations (using an optical microscope) and observations of the failure surfaces (using a Scanning Electron Microscope, SEM)) show that, for uniaxial loads (plane bending and tension-compression loading $\mathrm{R}=-1$ ), the fatigue cracks always initiate from pores (see Fig.11) in alloys A and B. These observations are in good agreement with experimental observations reported in the literature [1, 3, 4, $8,13-21]$

\subsubsection{Porosity-free material (alloy C)}

Two fatigue crack initiation mechanisms have been observed to operate in alloy $\mathrm{C}$ : the first mechanism is associated with persistent slip bands (PSB) formation and the second is controlled by oxide films. In the literature, these two crack initiation mechanisms have also been reported in the work of Wang et al. [5] and Zeng et al.[22]. 


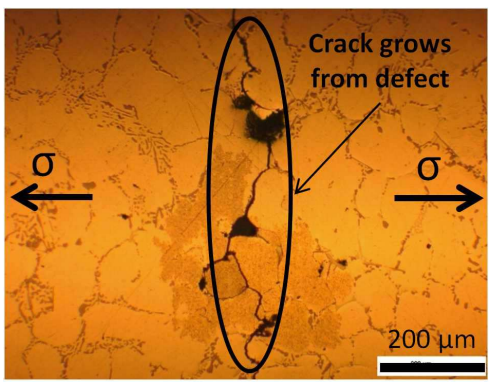

(a)

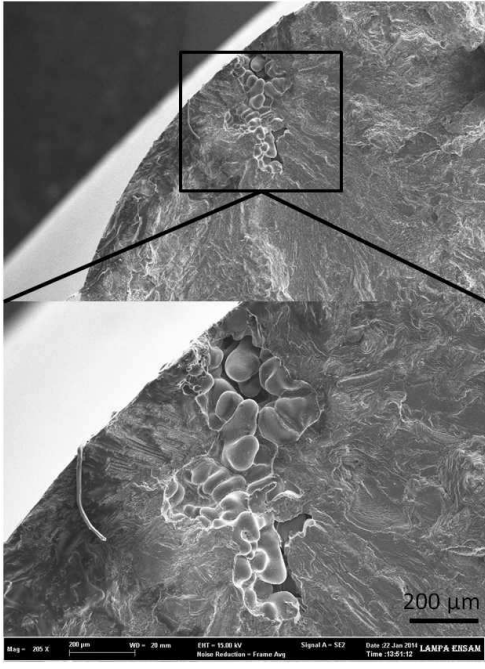

(b)

Figure 11: Fatigue crack initiation from a degassing pore in alloy $\mathrm{B}$ for the tension-compression load with an $\mathrm{R}=-1$ : a) Surface observation; b) observation of the failure surface

Crack initiation from PSB. : this mechanism was observed in 14 of 20 specimens. Fig 12 shows a fatigue crack which initiates from a PSB. The size of the crack initiation site is approximately $400 \mu \mathrm{m}$. This value is in good agreement with the mean value of the grain size of alloy $\mathrm{C}$ (see Fig, (5).

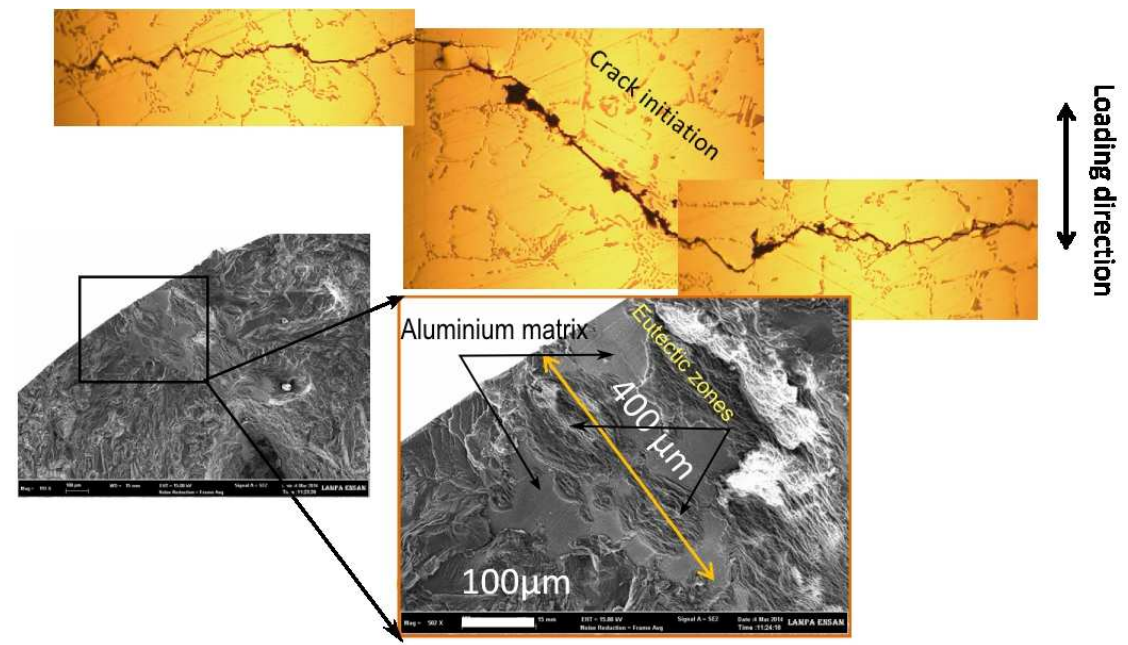

Figure 12: Crack initiation from PSB, observed on the specimen surface and on the failure surface of alloy C. The specimen is loaded in pure tension $\sigma_{x x, a}=120 \mathrm{MPa}, N_{f}=1.4 \times 10^{6}$ cycles 

to identify this initiation mechanism, energy-dispersive X-ray spectroscopy (EDS) analyses were used to determine the chemical compositions at the crack initiation sites. Fig 13 shows that oxygen and aluminium are the most abundant elements.
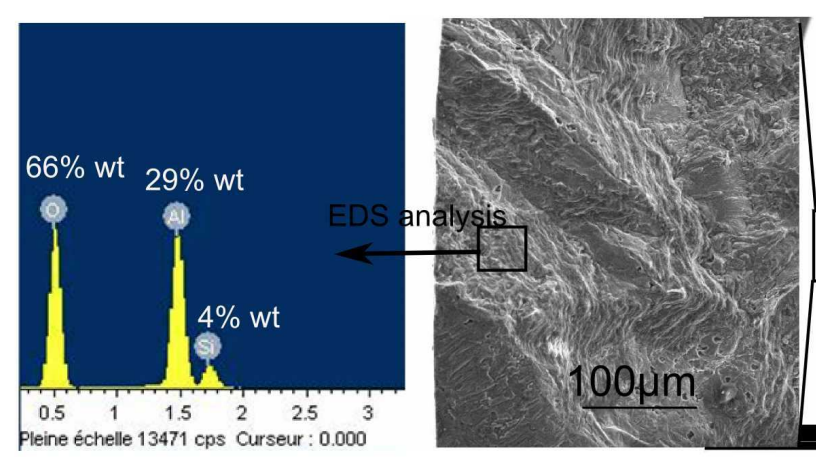

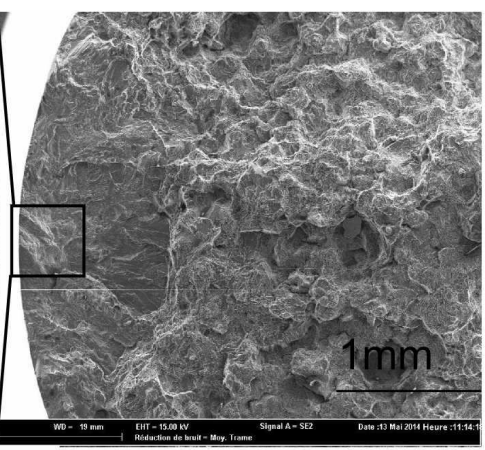

Figure 13: Crack initiation due to the presence of an oxide film in pure tension loads. The local chemical composition and SEM observations of the failure surface for a specimen of alloy $\mathrm{C}$

In the work of Koutiri et al.[1], the authors observed another crack initiation mechanism related to damage associated with silicon particles in eutectic zones (i.e. rupture or debonding of the silicon particles). However, it should be kept in mind that alloy A contains casting pores and that the authors observed that the "dominating" damage mechanism was related to the porosity. Following the observations of the crack initiation mechanisms in alloys $\mathrm{B}$ and $\mathrm{C}$ for uniaxial loading $\mathrm{R}=-1$ in which damaged silicon particles were not observed, it is proposed here that crack initiation in the eutectic zones of alloy A is probably caused by pores located just below the surface.

\subsection{Pure torsion loading}

\subsubsection{Porosity-containing materials (alloys $A$ and B)}

In the work of Koutiri et al.[1, 23], observations of the specimen surfaces as well as the fatigue failure surfaces of alloy A showed that crack initiation is not related to the porosity for pure torsional loads. According to the authors, when loaded in torsion, casting pores have much less influence when compared to the uniaxial loading condition. Concerning the principal fatigue cracks, for the majority of cases, cracks were observed to initiate in the plane of maximum shear 
stress, perpendicular to or parallel to the specimen axis. No crack bifurcation was observed during propagation.

For alloy B, two crack initiation mechanisms were observed: the first mechanism is related to crack propagation from pores located on the specimen surface and the second is controlled by PSB formation (see Fig 14). These two mechanisms coexist and have been observed on the same specimen.

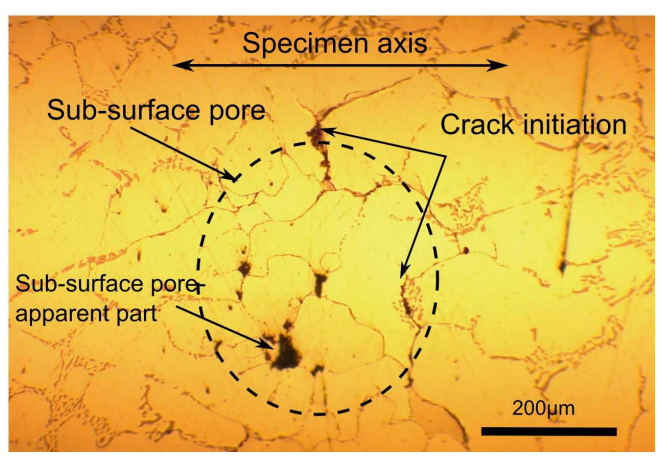

(a)

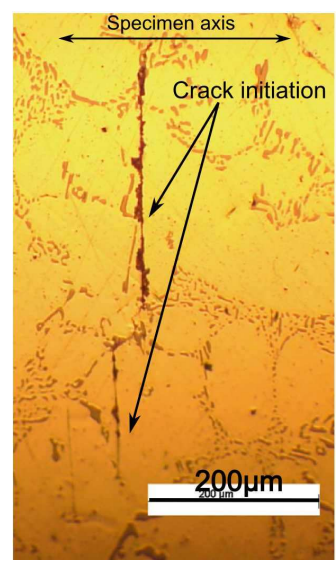

(b)

Figure 14: Two crack initiation mechanisms observed for the pure torsion loads of alloy B: a) Crack initiation at a pore; b) Crack initiation by PSB

Regarding the crack propagation mechanisms, a competition between two propagation mechanisms can be observed: the first one is related to the opening mode (mode I) and the second is controlled by the shear stress (mode II and III). Fig 15 shows the crack size and shape corresponding to different number of cycles of a fatigue crack observed on a specimen subjected to pure torsion with $\tau_{x y}=80 \mathrm{MPa}(\mathrm{R}=-1)$.

\subsubsection{Porosity-free material (alloy C)}

For alloy $\mathrm{C}$, it is observed that crack initiations are always controlled by PSB formation (see Fig. (16).

It has also been observed that many cracks related to PSB were blocked by grain boundaries (or dendrite boundaries) when the crystallographic orientations of the blocking grains are not favourable in terms of the crack growth direction (see Fig.17) 


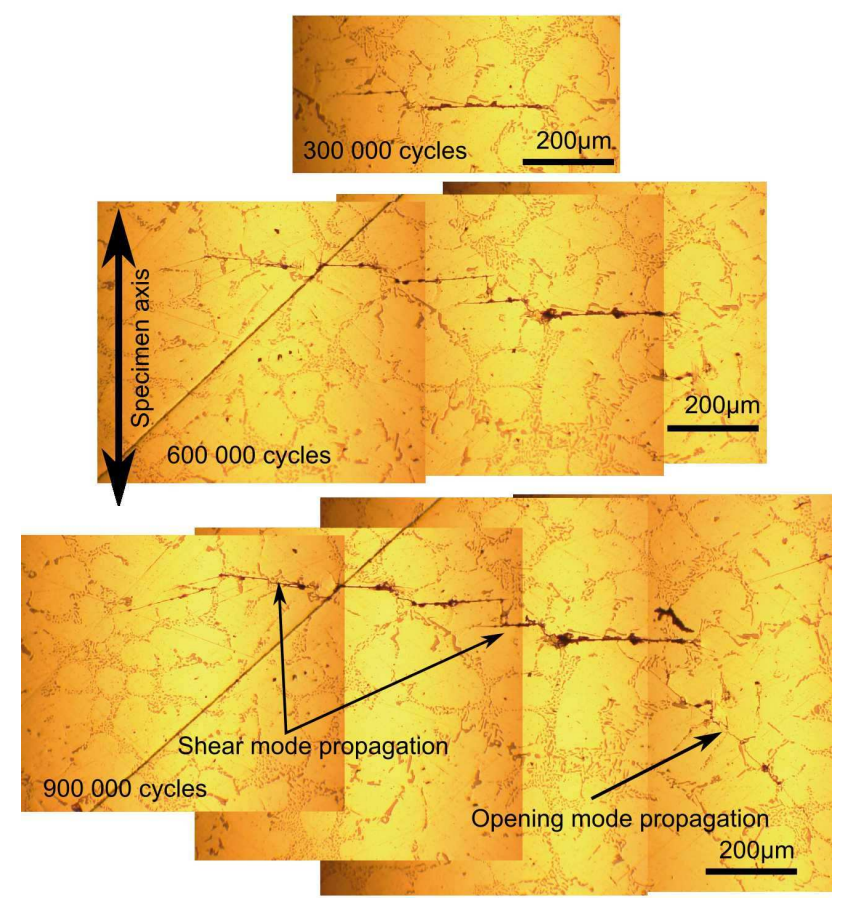

Figure 15: Crack growth observation for an alloy B specimen subjected to pure torsion with $\tau_{a}=80 M P a, N_{f}=$ $1.9 \times 10^{6}$ cycles

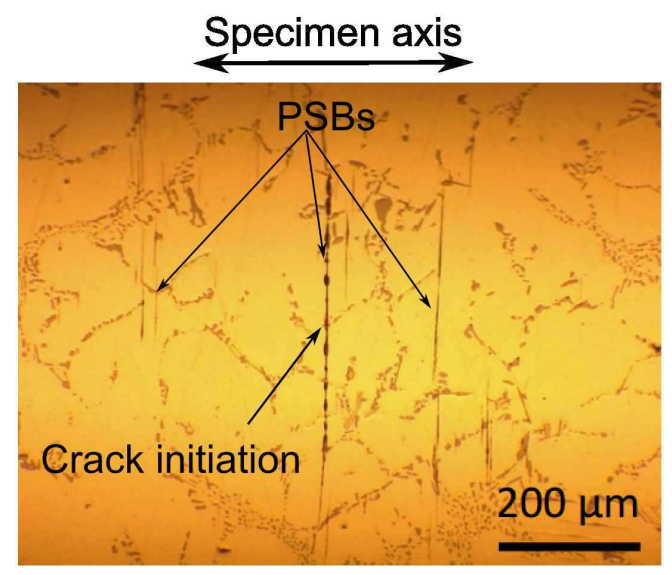

Figure 16: Crack initiation from PSB observed on the specimen surface of alloy $\mathrm{C}$ subjected to pure torsion with $\tau_{a}=70 \mathrm{MPa}$ at $N=2.10^{6}$ cycles

Concerning crack growth, for the majority of cases fatigue cracks propagate due to a shear mode for pure torsion loads. However, it is possible to observe crack bifurcation controlled by either a shear mode or by the opening mode. 

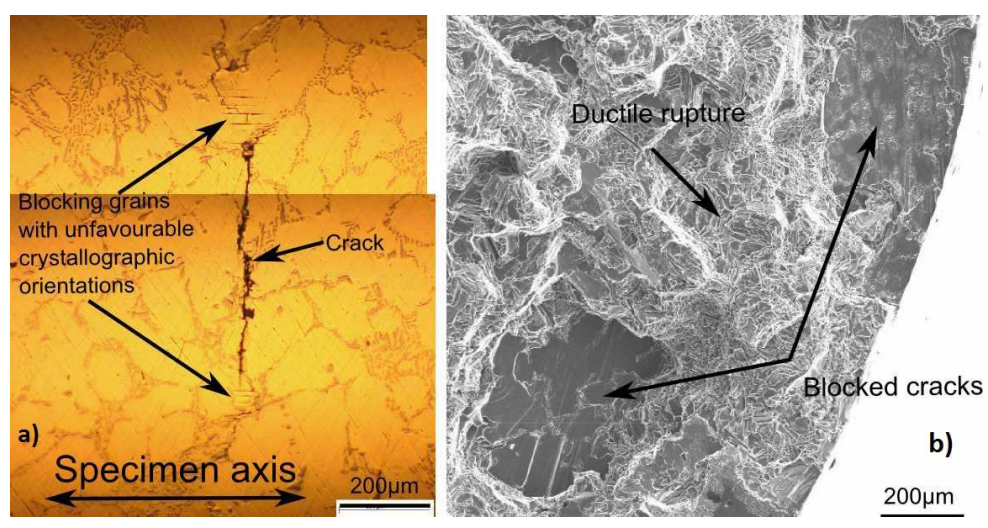

Figure 17: Blocked cracks due to the grains with unfavourable crystallographic orientation observed on a specimen surface (a) and on a failure surface (b) for the pure torsional load of the alloy $\mathrm{C}$

\subsection{Combined tension-torsion loading with $k=\tau_{a} / \sigma_{a}=0.5$}

The fatigue damage mechanisms in combined tension-torsion with a biaxiality ratio $k=\tau_{a} / \sigma_{a}=$

0.5 are similar to those observed for the pure tension-compression load case. That is:

- for the porosity-containing alloys (alloys A and B), fatigue cracks initiate from pore and grow in the plane of maximum normal stress;

- for the porosity-free alloy (alloy C), fatigue cracks initiate from PSB and grow in the plane of maximum normal stress.

\subsection{Summary of fatigue damage mechanisms}

Fig 18 summarises the crack initiation mechanisms observed on the surface of the three alloys for the different loading modes.

- For pure tension and combined tension-torsion loads: fatigue cracks always initiate and propagate from pores for the porosity-containing materials (alloys A and B) while for the porosity-free alloy (alloy C), fatigue cracks initiate from persistent slip bands (PSB).

- For pure torsional load: for the porosity-containing alloys (alloys A and B), two crack initiation mechanisms have been observed: the first mechanism is related to crack propagation from casting pores located on the specimen surface and the second is controlled by PSB 

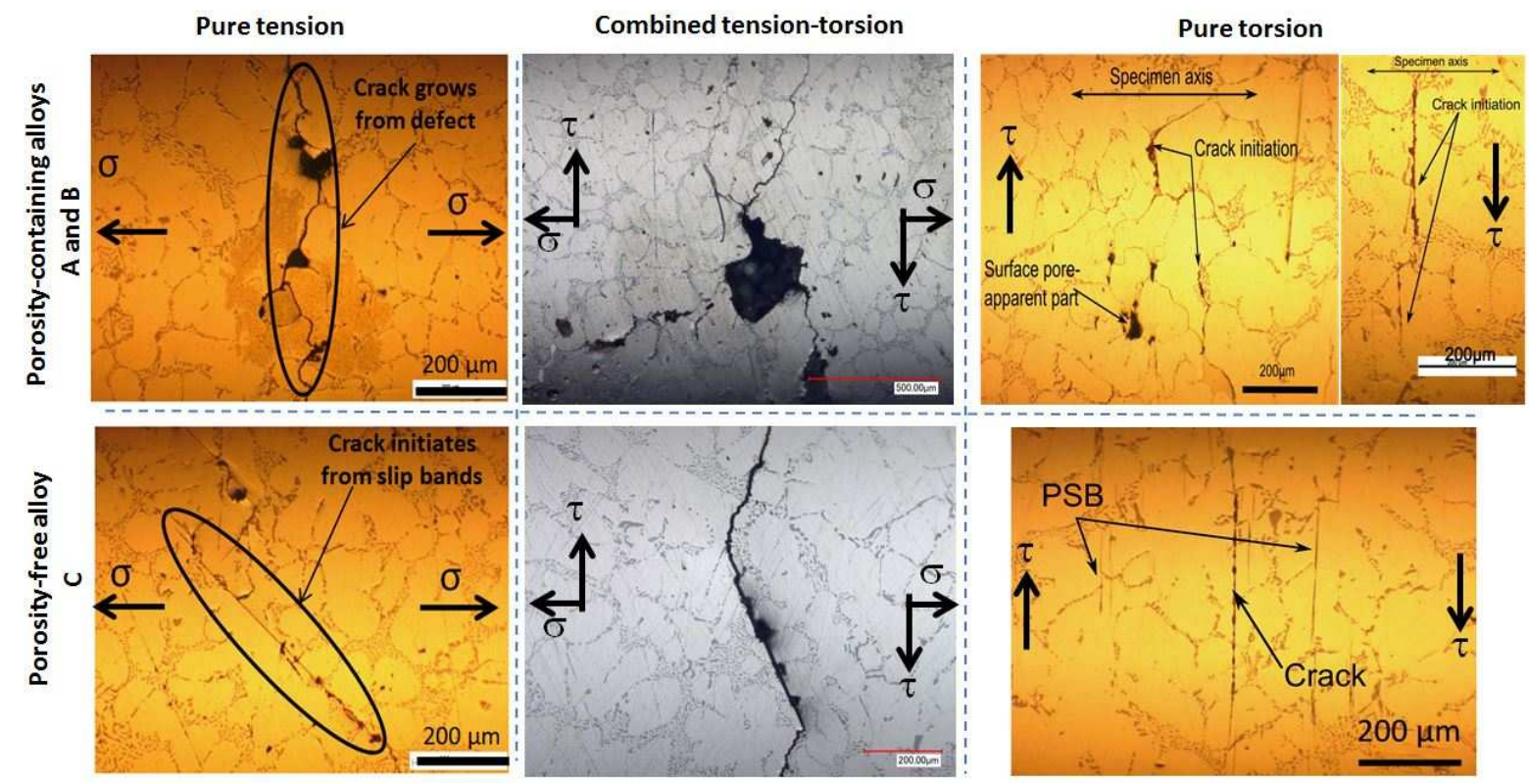

Figure 18: Fatigue damage mechanisms of alloys $\mathrm{A}, \mathrm{B}$ and $\mathrm{C}$ for three loading modes (pure tension, combined tension-torsion and pure torsion), observed on the specimen surfaces

formation. These two mechanisms coexist and have been observed on the same specimen. For the porosity-free alloy (alloy C), only the crack initiation mechanism related to PSB formation was observed.

Based on these fatigue damages mechanism observations, the change in the ratio between the torsional fatigue strength and the uniaxial fatigue strength $\left(\tau_{a, D} / \sigma_{a, D}\right)$ mentioned in the Section 3 can be explained by the fact that casting pores have lower influence when loaded in pure torsion, compared to the other loading conditions (tension-compression and combined tension-torsion) for the porosity-alloys (alloys A and B).

The difference in the relative standard deviation of the fatigue strengths ( $\operatorname{see} \mathrm{Sec}$. 3) can be explained by the fact that the fatigue damage mechanism for alloy $\mathrm{C}$ is related to PSB formation regardless of loading modes while for alloys $\mathrm{A}$ and $\mathrm{B}$, the fatigue damage mechanism is controlled by crack propagation from pores, particularly for uniaxial loads and combined tension-torsion load. This explanation is confirmed by the lower scatter associated with the fatigue strength for the pure torsion load, compared to the tension-compression and combined tension-torsion loads, for alloys A and B. 


\section{Roles of aluminium matrix and silicon particles in PSB formation in pure torsion load}

measurements were undertaken on three specimens with the geometry shown in Fig.7. These specimens were subjected to a pure torsional load $(\mathrm{R}=-1)$ until the presence of PSB were observed (see Fig,19). Tab 6 summaries the test conditions.

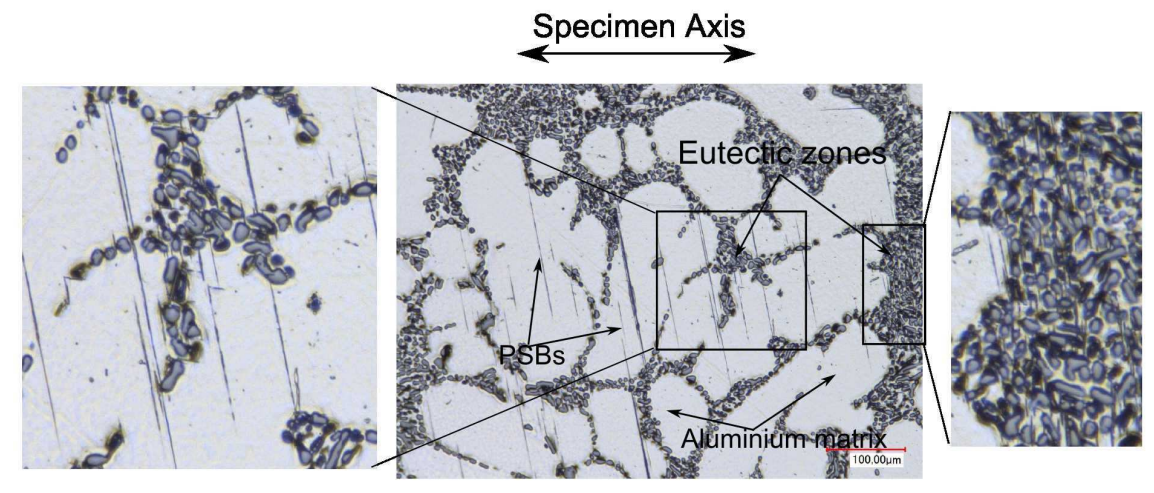

Figure 19: PSB observed on an alloy $\mathrm{C}$ specimen subject to pure torsion with $\tau_{a}=80 \mathrm{MPa}$ at $\mathrm{N}=2.2 \times 10^{6}$ cycles

\begin{tabular}{cccc}
\hline Alloy & Specimen & $\begin{array}{c}\tau_{\max }(\mathrm{MPa}) \\
\text { in the observation zone }\end{array}$ & Number of cycles \\
\hline A & 1 & 90 & $2.5 \times 10^{6}$ \\
\hline C & 2 & 80 & $2.2 \times 10^{6}$ \\
\hline C & 3 & 90 & $1.3 \times 10^{6}$ \\
\hline
\end{tabular}

Table 6: Resume of pure torsion loading test for EBSD observations

In order to analyse the influence of the crystallographic orientations on PSB formation, the

effective Schmid factor (ESF), introduced by Agbessi et al. and Robert et al.[24, 25], is used. This 
factor is defined by $\mathrm{Eq} 4$ to 6 .

$$
\begin{gathered}
f_{e f f, g}^{s}=\max _{t}\left(\frac{\tau_{g}^{s}(t)}{\Sigma_{I}(t)}\right) \\
\tau_{g}^{s}(t)=\underline{m^{s}} \cdot \underline{C}(t) \\
\underline{C}(t)=\underline{\Sigma_{n}}(t)-\underline{N}(t)=\underline{\underline{\Sigma}}(t) \cdot \underline{n^{s}}-\left(\underline{n}^{s} \cdot \underline{\underline{\Sigma}}(t) \cdot \underline{n}^{s}\right) \underline{n}^{s}
\end{gathered}
$$

where $\tau^{s}(t)$ is the resolved shear stress on slip system $s$ defined by the normal vector $\underline{n}^{s}$ and the slip direction vector $\underline{m}^{s}$ of grain $g . \underline{\underline{\Sigma}}(t), \underline{\Sigma_{n}}(t)$ and $\Sigma_{I}(t)$ are the stress tensor, the normal stress vector and the largest component of the principal stress tensor at the macroscopic scale, $\underline{\underline{\Sigma_{P}}}(t)$. Using this definition of ESF, the maximum value of the ESF is 0.5 for uniaxial loads and 1.0 for pure torsional load. After obtaining the Euler angles of the grains using EBSD data, the ESF corresponding to each slip system of grains is determined. Because aluminium has a face-centred cubic (fcc) crystal structure, there are 12 slip systems constituted from 4 slip plans $\{111\}$ and 3 directions $<110>$.

Firstly, the experimentally observed directions of the PSB were compared with the theoretical predictions for the slip systems of each grain. It were observed that the experimentally observed directions are always aligned with the theoretical directions of the slip planes in which the ESF is maximum of the four slips planes $\{111\}$. However, it is impossible to determine the direction (between the 3 directions $<110>$ ) in which the observed PSB were formed. Therefore, it is assumed that the experimentally observed PSB correspond to the slip system which maximizes the ESF.

Furthermore, because the flat zone, machined on the specimen surface to facilitate the EBSD measurements, is relatively large compared to the cross section of the specimen, its presence leads to an high stress gradient in this zone. Therefore, it is drawn the relationship between the probability of occurrence of PSB against the maximum resolved shear stress instead of against the ESF. The maximum resolved shear stress is calculated by the following equation:

$$
\tau_{e f f, g}(t)=\max _{i=1.12}\left(f_{e f f, g}^{s_{i}}\right) \cdot \Sigma_{I}(t)
$$


where $f_{e f f, g}^{s_{i}}$ is the ESF corresponding to slip system $s_{i}$ of the grain $g$ and $\Sigma_{I}(t)$ is the largest component of the principal stress tensor at macroscopic scale applied on grain $g, \Sigma_{P}^{g}(t)$. This stress is determined from a 3D finite element simulation of the specimen in which an isotropic elastic grains in total considered in each sample.

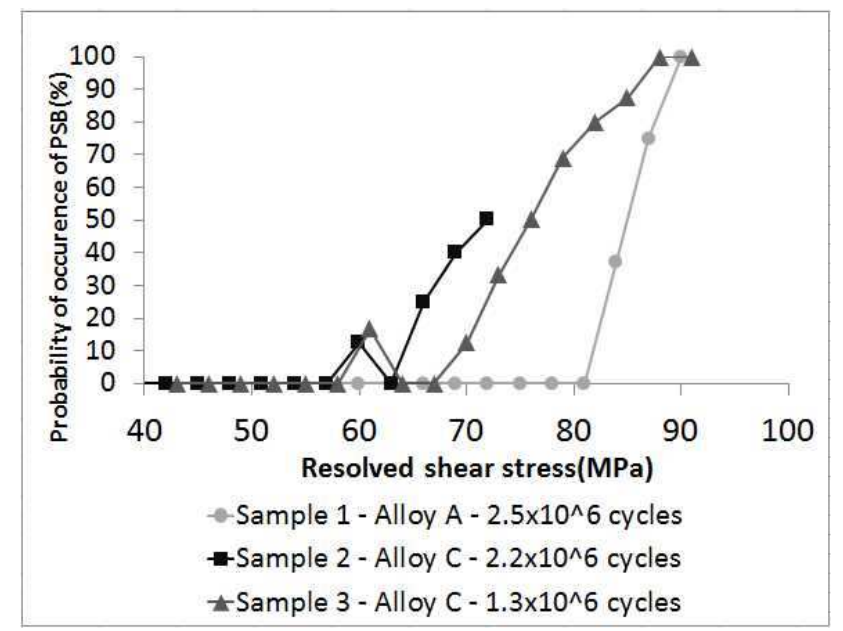

Figure 20: Relationship between the probability of occurrence of PSB and the maximum resolved shear stress

This figure shows that the occurrence probability of PSB depends on the resolved shear stress. The threshold of the resolved shear stress resulting in the apparition of the first PSB is highlighted. The comparison between the two alloy $\mathrm{C}$ specimens (specimens 2 and 3) shows that this threshold number of cycles necessary for the formation of the first PSB is higher. This relationship was also observed in the works of [24, 26].

By comparing the sample 1 (alloy A) and sample 2 (alloy C) the influence of the aluminium matrix can be determined. These specimens were loaded until approximately the same number of 
cycles. However, an significant difference of the threshold of the resolved shear stress between these two alloys is observed. This difference can be explained by the following factors:

- The precipitation hardening level: alloy A (AlSi7Cu05Mg03-KT7) contains an additional $0.5 w t . \%$ copper compared to alloys B and C. Therefore the hardening precipitates of alloy A are mostly binary precipitates $\beta^{\prime}\left(\mathrm{Mg}_{2} \mathrm{~S} i\right)$ and quaternary precipitates $Q^{\prime \prime} / Q^{\prime}\left(\mathrm{Al}_{5} \mathrm{Cu}_{2} \mathrm{Mg}_{8} \mathrm{Si}_{7}\right)$ [27]. For alloys B and C, the absence of copper is assumed to lead to a lower volume fraction of hardening precipitates of the alpha phase. This effect can be observed via the comparison of the micro-hardness of the alpha matrix between the three alloys: the micro-hardness of alloy A (113.8 $\pm 2.8 \mathrm{Hv} 0.025)$ is the highest while the one of alloys B $(99 \pm 9 \mathrm{Hv} 0.025)$ and alloy $\mathrm{C}(92 \pm 13 \mathrm{Hv} 0.025)$ are relatively similar given the scatter.

- The SDAS: alloy A has a finer microstructure than alloy $\mathrm{C}\left(S D A S_{A}<S D A S_{C}\right)$. The SDAS could influence the threshold the resolved shear stress via the grain boundary effect. However, this effect has not been investigated in the present work.

\subsection{The role of silicon particles}

It is seen in Fig 19 that the majority of PSB initiate from silicon particles. This fact suggests that the silicon particles facilitate PSB formation. In order to investigate the competition of the roles of the aluminium matrix and the silicon particles in the formation of PSB, Fig, 21 shows a comparison of the maximum effective Schmid factors of the grains without PSB and the grains in which PSB are observed. Because the observations zone is small, the calculation of the resolved shear stress is not necessary .

It is shown that PSB initiation occurs only at silicon particles related to the grains having a high ESF (grains 1 and 4). No PSB was observed in grains 2 and 3.

Also, it can be seen in Fig 19 that PSB also initiate at silicon particles in the eutectic zones. However the high density of silicon particles in these zones can confine the development of PSB in these area. 


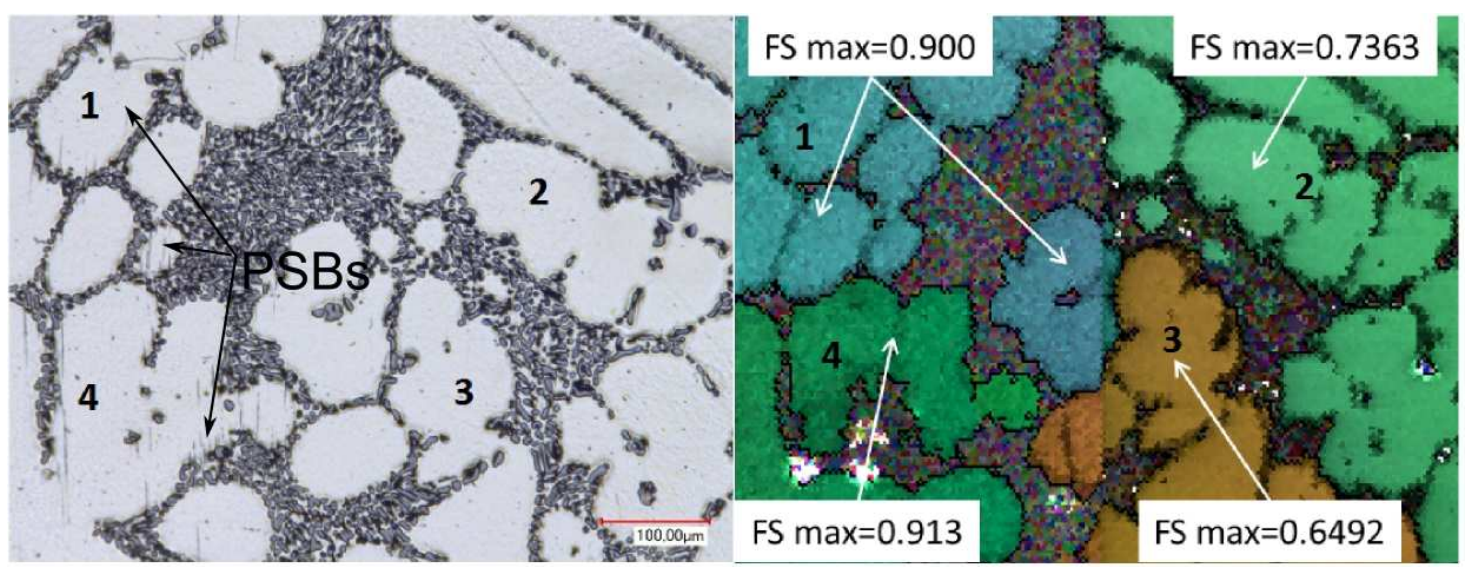

Figure 21: Comparison of the ESF max of the grains with PSB and the grains without PSB

\subsection{Partial conclusion}

Thank to analysis in Sec5.1 and 5.2, the following conclusions can be made for pure torsion loads at $\mathrm{R}=-1$ :

- the role of the crystallographic orientations, the precipitation hardening level and the SDAS of the aluminum matrix are the major factors defining in which grain PSB formation occurs;

- the silicon particles play the role of initiating the PSB, only if the conditions above are satisfied and given that silicon particles can be found surrounding all grains, the role of the si particles is not decisive in PSB formation.

It would not be unreasonable to assume that this conclusion is valid for uniaxial loads with $\mathrm{R}=-$ 1 because crack initiation is principally controlled by PSB formations and no cracked or debonded Si particles were observed at the crack initiation sites for alloy C. However, for a loading condition with higher hydrostatic stress (for example uniaxial loads with positive load ratio), this conclusion may no longer be valid. For example, the work of Dezecot and Brochu [28] shows a more detrimental role of Si particles (cracked and/or debonded Si particles observed in crack initiation sites) in cast aluminum alloys for uniaxial loads at $\mathrm{R}=0.1$.

Thank to this analyse, the higher torsional fatigue strength of alloy A compared to alloy C (see Sec 3) can be explained by the following factors: 
- A lower influence of the porosity on the torsional fatigue strength: even thought alloy A contains casting pores, the fatigue damage mechanism related to the formation of PSB dominates for the pure torsion load.

- The precipitation hardening level of the alpha phase: alloy A contains an additional $0.5 \%$ wt. copper compared to alloys B and C. This give alloy A a higher critical shear stress compared to alloys $\mathrm{B}$ and $\mathrm{C}$.

However, it should be kept in mind that it has been assumed that there is no effect of the grain boundaries (or the effect of grain size / SDAS) on the stress field when calculating the resolved shear stress. In the literature, the effect of the SDAS on the fatigue strength of the porosity-free alloys has not been well investigated. The following exceptions can be noted:

- For uniaxial loads: Wang et al.[5], Gao et al.[20] and Redik et al.[6] observed that for a SDAS from 30 to $60 \mu \mathrm{m}$, when the SDAS is increased, the fatigue strength decreases for a load ratio of $\mathrm{R}=-1$. In the interval of SDAS from 60 to $80 \mu m$, when the SDAS is increased, the fatigue strength increases [5]. However, Houria et al.[29] observed that the influence of the SDAS on the fatigue strength for uniaxial loads at $\mathrm{R}=-1$ is not significant.

- For multiaxial loads: only the work of Houria et al.[29] was found which investigated the effect of SDAS on the torsional fatigue strength. They observed that when the SDAS is increased, the torsional fatigue strength at a load ratio of $\mathrm{R}=-1$ decreases.

The literature highlights the complicated role of the SDAS on the fatigue strength. Hence, more work is needed to completely understand the role of SDAS and its interaction with the precipitate hardening level in the alpha phase, for the formation of PSB.

\section{Influence of the casting pores on the fatigue strength for different loading modes}

\subsection{Influence of defect for the tension-compression and combined tension-torsion loads}

In order to investigate the influence of casting pores on the fatigue strengths, the failure surfaces were examined. The specimens that survived $2 \times 10^{6}$ cycles in the staircase procedure were retested 
at a stress amplitude one step higher, or $10 \mathrm{MPa}$ higher for an additional $2 \times 10^{6}$ cycles. This was repeated until failure of the specimen after less than $2 \times 10^{6}$ cycles. The fatigue strength of the specimen was then taken to be the stress level of the final step. This method was firstly proposed by Maxwell et al.[30] and is regularly used by Nadot and co-workers for HCF tests of cast aluminium alloys [8, 13, 14].

The failure surfaces were examined and the pore at the origin of the principal crack was identified and measured using an Scanning Electro Microscopy (SEM). Fig.22 shows an example of defect area measurement.

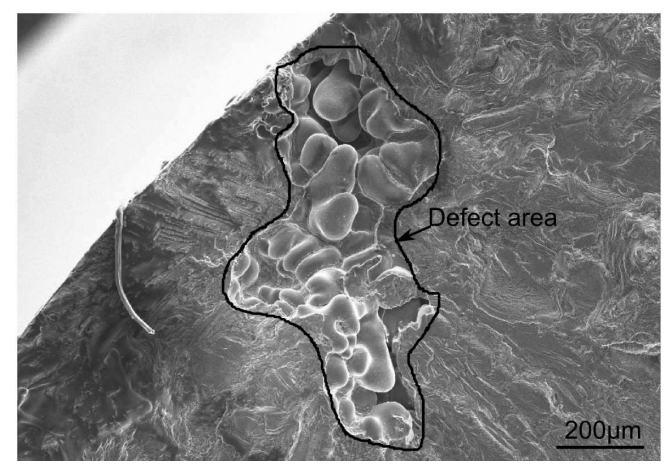

Figure 22: Defect size measurement by observation of failure surface

Fig 23 shows the experimentally determined fatigue strengths as as function of the experimentally determined defect size for alloys A and B for the tension-compression and combined tension-torsion loads.For each case, the experimental data are compared to the fatigue strength predictions using the LEFM criterion in which the fatigue strength is determined by the following expression ([9]):

$$
2 . \sigma_{I, a, D}=\frac{\Delta K_{t h}}{0.65 \sqrt{\pi \sqrt{\text { area }}}}
$$

where $\sigma_{I, a}$ is the amplitude of the principal stress and $\Delta K_{t h}$ is the range of stress intensity factor (SIF) threshold in pure tension loading $\mathrm{R}=-1$. These stress intensity thresholds have been arbitrarily estimated to match the experimental data.

In the literature, no data concerning the stress intensity threshold of artificial long cracks for uniaxial load $\mathrm{R}=-1$ was found for cast Al-Si alloys. However, threshold data for a load ratio of $\mathrm{R}=0.1$ has been reported by [17, 19, 31], in which the threshold values for long cracks are 


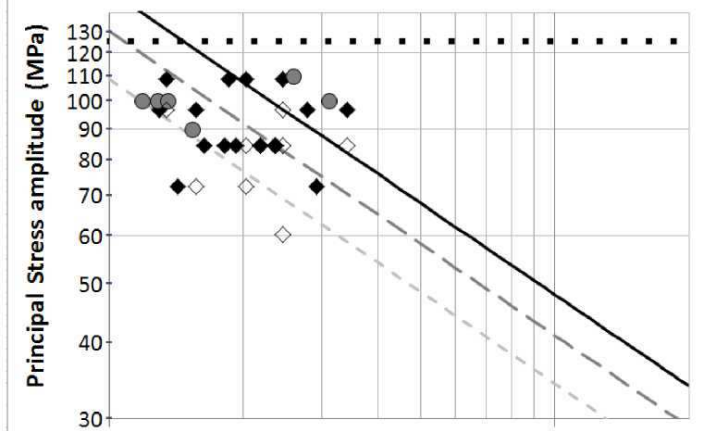

a) $100 \quad$ Defect size $-(\text { area })^{1 / 2}(\mu \mathrm{m}) 1000$

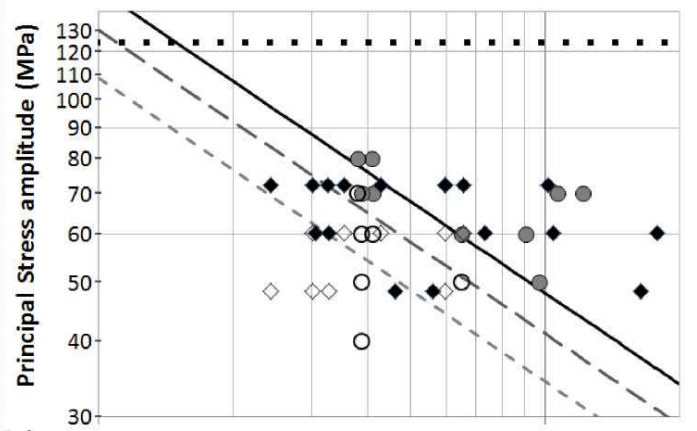

b) $100 \quad$ Defect size $-(\text { area })^{1 / 2}(\mu \mathrm{m}) 1000$

\section{$-\Delta \mathrm{Kth}=3 \mathrm{MPa} \cdot \mathrm{m} 1 / 2 \quad \mathrm{O} / \mathrm{O}$ Uniaxial loading: no failure/failure $\Delta \mathrm{K}$ th=2.5MPa. m1/2 $\diamond / \diamond$ Combined tension- torsion: no failure/failure \\ $--\Delta \mathrm{Kth}=2 \mathrm{MPa} . \mathrm{m} 1 / 2$ ... - Pure tension fatigue strength of porosity-free alloy (alloy $\mathrm{C}$ )}

Figure 23: Experimentally determined fatigue strengths as a function of the experimentally determined defect size for alloys A (a) and B (b) in uniaxial and combined tension-torsion load

estimated to be $\Delta K_{t h}=4$ to $5 M P a \sqrt{m}$. Compared to the stress intensity threshold estimated in Fig 23 of approximately 2 to $3 M P a \sqrt{m}$ at $\mathrm{R}=-1$, it can be assumed that the small crack effect is significant for the propagation of natural fatigue cracks. In addition, it can be seen that the intersection of the fatigue strength of the porosity-free alloy (alloy $\mathrm{C}$, the horizontal dotted line corresponding to $126 \mathrm{MPa}$ ) and the predictions using the LEFM criterion is approximately $\sqrt{\text { area }}=100$ to $200 \mu m$. Consequently, it can be supposed that the critical defect size related to the uniaxial and combined tension-torsion loads is approximately $\sqrt{\text { area }} \approx 100$ to $200 \mu m$.

\subsection{Influence of defect on pure torsion load fatigue strength}

As mentioned earlier in Sec4 two fatigue damage mechanisms have been observed for the pure torsional loads in alloy B: the first one is related to crack propagation from casting defect in the opening mode; the second is controlled by the crack initiation from PSB followed by crack propagation in shear mode. Hence, the defects observed on the failure surfaces related to each mechanism were identified and measured. Fig 24 shows the relationship between the defect size and the experimentally determined fatigue strengths corresponding to these two mechanisms. The defect size corresponds to the projected area $\sqrt{\text { area }}$ on the plane perpendicular to the specimen axis. It is important to note that for the second mechanism, because crack initiation and crack 
propagation are controlled by the same mechanism (i.e. the shear mode), the reported defect size corresponds to the biggest defect observed on the failure surface.

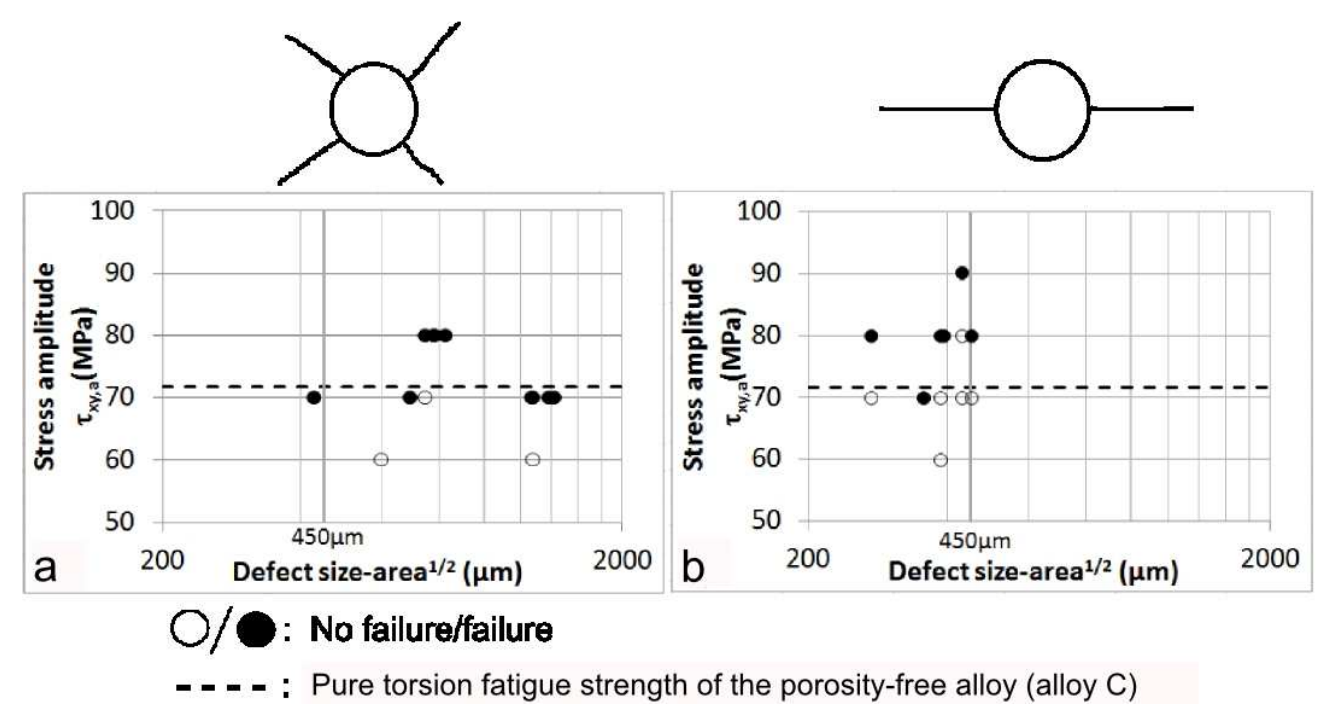

Figure 24: Experimentally determined fatigue strengths as a function of the experimentally determined defect size for alloy B in pure torsional loads: a) the first fatigue mechanism related to the crack propagation from pores in opening mode; b) the second mechanism related to crack initiation from PSB followed by crack propagation due to the shear modes

Firstly, it can be seen that the defect size related to the first mechanism is larger than the one corresponding to the second mechanism and that a defect size $\sqrt{\text { area }}$ of $450 \mu m$ defines the boundary between the two mechanisms. In addition, it is shown a slight increase in the stress level corresponding to the final step: for the first mechanism Fig.24a), at $\tau_{x y, a}=70 \mathrm{MPa}, 80 \%$ of specimens failed while for the second mechanism (Fig, 24b), $80 \%$ specimens survived. Hence, the defect size threshold of $450 \mu \mathrm{m}$ can be considered as the critical defect size below which defects have negligible influence on the pure torsion fatigue strength. It is important to note that this threshold value is the same order of magnitude as the average grain area square root $\sqrt{\text { area }}$ average in alloy $\mathrm{C}$ which is $\sqrt{\text { area }}_{\text {average }}=D_{\text {e,average }} \cdot \sqrt{\pi} / 2 \approx 411 \mu m$ (see Fig 5 ). This value is supposed similar to that for alloy B. 


\section{Conclusions}

The principal objective of this work was to better understand the HCF behaviour of the cast aluminium alloys under various uniaxial and multiaxial loading modes with a load ratio of $\mathrm{R}=-$ 1. Three different cast aluminium alloys were investigated. These materials were fabricated by different casting processes (gravity die cast, lost foam cast) and subject to different heat treatments (T7, HIP). These different processes lead to three very different defect size distributions for the three alloys investigated.

- The characterization of the HCF damage mechanisms shows very different crack initiation as well as crack propagation mechanisms, depending on loading modes.

- An investigation of PSB formation highlights the role of the aluminium matrix (via the crystallographic orientation, the precipitation hardening level and the SDAS) and the role of silicon particles for pure torsion load at $\mathrm{R}=-1$.

- Via the investigation of the pore at the origin of the principal fatigue crack, it was shown that a) the small crack effect is significant for natural fatigue cracks and b) pores have less influence on the pure torsion fatigue strength compared to tension-compression and combined tension-torsion loads.

\section{Acknowledgement}

This work was financially supported be PSA Peugeot Citroën.

\section{References}

\section{References}

[1] Imade Koutiri, Daniel Bellett, Franck Morel, Louis Augustins, and Jérme Adrien. High cycle fatigue damage mechanisms in cast aluminium subject to complex loads. International Journal of Fatigue, 47(0):44 - 57, 2013.

[2] Q.G Wang, D Apelian, and D.A Lados. Fatigue behavior of a356-t6 aluminum cast alloys. part i. effect of casting defects. Journal of Light Metals, 1(1):73 - 84, 2001.

[3] D.L McDowell, K Gall, M.F Horstemeyer, and J Fan. Microstructure-based fatigue modeling of cast a356-t6 alloy. Engineering Fracture Mechanics, 70(1):49 - 80, 2003. 
[4] J-Y. Buffière, S. Savelli, P.H. Jouneau, E. Maire, and R. Fougères. Experimental study of porosity and its relation to fatigue mechanisms of model alsi7mg0.3 cast al alloys. Materials Science and Engineering: A, 316(12):115 $-126,2001$.

[5] Q.G Wang, D Apelian, and D.A Lados. Fatigue behavior of a356/357 aluminum cast alloys. part \{II $\}$ effect of microstructural constituents. Journal of Light Metals, 1(1):85 - 97, 2001.

[6] Redik, Sabine, Tauscher, Markus, and Grn, Florian. Mechanisms of fatigue-crack initiation and their impact on fatigue life of alsi7 die-cast components. MATEC Web of Conferences, 12:03003, 2014.

[7] JamesM. Boileau and JohnE. Allison. The effect of solidification time and heat treatment on the fatigue properties of a cast 319 aluminum alloy. Metallurgical and Materials Transactions A, 34(9):1807-1820, 2003.

[8] P. Mu, Y. Nadot, C. Nadot-Martin, A. Chabod, I. Serrano-Munoz, and C. Verdu. Influence of casting defects on the fatigue behavior of cast aluminum as7g06-t6. International Journal of Fatigue, 63(0):97 - 109, 2014.

[9] Y. Murakami. Effects of small defects and nonmetallic inclusions. Elsevier, 2002.

[10] Bruno Barlas. Etude du comportement et de lendommagement en fatigue dalliages daluminium de fonderie. $\mathrm{PhD}$ thesis, Ecole des Mines de Paris, 2004.

[11] L. Ceschini, Alessandro Morri, Andrea Morri, A. Gamberini, and S. Messieri. Correlation between ultimate tensile strength and solidification microstructure for the sand cast a357 aluminium alloy. Materials and Design, 30(10):4525 - 4531, 2009.

[12] Kyuhong Lee, Yong Nam Kwon, and Sunghak Lee. Effects of eutectic silicon particles on tensile properties and fracture toughness of $\{$ A356 $\}$ aluminum alloys fabricated by low-pressure-casting, casting-forging, and squeezecasting processes. Journal of Alloys and Compounds, 461(12):532 - 541, 2008.

[13] M.J. Roy, Y. Nadot, C. Nadot-Martin, P.-G. Bardin, and D.M. Maijer. Multiaxial kitagawa analysis of a356-t6. International Journal of Fatigue, 33(6):823 - 832, 2011.

[14] M. ROY, Y. NADOT, D. M. MAIJER, and G. BENOIT. Multiaxial fatigue behaviour of a356-t6. Fatigue and Fracture of Engineering Materials and Structures, 35(12):1148-1159, 2012.

[15] Y. Nadot, A. Chabaud, I. Serrano Mura, P. Mu, C. Verdu, J. Y. Buffire, P. Emile, C. Richard, and L. Anssems. Influence of defect on the fatigue behaviour of as $7 \mathrm{~g} 06 \mathrm{t} 6$ aeronautical alloy (ideffaar). In The 2nd International Symposium on Fatigue Design and Material Defects. SF2M, 062014.

[16] M.J.Caton, J.W.Jones, H.Mayer, S. Stanzl-Tschegg, and J.E.Allison. Demonstration of an endurance limit in cast 319 aluminum. Metallurgical and Materials Transactions A, 34(11):33-41, 2003.

[17] M.J Caton, J.W Jones, and J.E Allison. The influence of heat treatment and solidification time on the behavior of small-fatigue-cracks in a cast aluminum alloy. Materials Science and Engineering: A, 314(12):81 - 85, 2001.

[18] Kwai S. Chan, Peggy Jones, and Qigui Wang. Fatigue crack growth and fracture paths in sand cast $\{$ B 319$\}$ and \{A356\} aluminum alloys. Materials Science and Engineering: A, 341(12):18 - 34, 2003.

[19] B. Skallerud, T. Iveland, and G. Hrkegrd. Fatigue life assessment of aluminum alloys with casting defects. 
Engineering Fracture Mechanics, 44(6):857 - 874, 1993.

[31] M. J. Couper and J. R. Griffiths. Effects of crack closure and mean stress on the threshold stress intensity factor for fatigue of an aluminium casting alloy,. Fatigue and Fracture of Engineering Materials and Structures, 13(6):615-624, 1990. 